\title{
A Novel Permanent Magnet Flux Switching Machine with an Outer-Rotor Configuration for In-Wheel Light Traction Applications
}

\author{
Weizhong Fei, Patrick Chi Kwong Luk, Senior Member, IEEE, Jianxin Shen, Senior Member, IEEE, \\ Yu Wang, and Mengjia Jin
}

\begin{abstract}
This paper proposes a novel permanent magnet flux switching (PMFS) machine with an outer-rotor configuration for in-wheel light traction applications. The geometric topology of the outer-rotor PMFS machine is introduced and the analytical sizing equations are derived to determine the main design parameters of the machine. Two-dimensional (2-D) Finite element analysis (FEA) models are developed to investigate and optimize the machine performance. Furthermore, the flux weakening capability of the machine is analyzed and further improved by segmental permanent magnets with iron bridges. The machine performance predictions by 2-D FEA models are validated by experimental tests on the prototype machine. The suitability of the proposed outer-rotor PMFS machine for in-wheel light traction application is demonstrated.
\end{abstract}

Index Terms - Back electromotive force, cogging torque, finite element analysis, flux switching, flux weakening, light traction, outer rotor, permanent magnet machine.

\section{INTRODUCTION}

U rban pollution and traffic congestion have been two of the most pressing issues in our cities. They have direct adverse impacts on the health of the citizens and the productivity of the cities. Electric propelled light traction vehicles, with zero tailpipe emission and great agility in traffic, provide ideal solutions to alleviate these problems. Thus, the demands for electric scooters, rickshaws and bicycles have grown very rapidly, in particular in countries such as India and China $[1,2]$. Currently, there is a trend to use in-wheel motors for such electric vehicles due to their compactness. An outer-rotor configuration provides higher torque density than an axial-flux or inner-rotor one in a low-speed in-wheel drive, and is therefore particularly suitable for in-wheel light traction applications. For the motor itself, the permanent magnet (PM) type offers high efficiency and compactness which are additional benefits for electric vehicles.

Manuscript received September 26, 2011;revised January 15, 2012; accepted March 18, 2012. Paper 2011-EMC-065.R1, presented at the 2010 IEEE Energy Conversion Congress and Exposition, Atlanta, GA, September 12-16, and approved for publication in the IEEE TRANSACTIONS ON INDUSTRY APPLICATIONS by the Electric Machines Committee of the IEEE Industry Applications Society.

W. Fei and P. C. K. Luk are with the Department of Offshore, Process and Energy Engineering, School of Engineering, Cranfield University, Cranfield, MK43 0AL, U.K. (e-mail: w.fei@cranfield.ac.uk; p.c.k.luk@cranfield.ac.uk).

J. X. Shen, Y. Wang, and M. J. Jin are with College of Electrical Engineering, Zhejiang University, Hangzhou, 310007, China (e-mail: j_x_shen@zju.edu.cn;

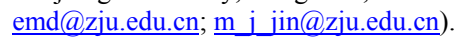

The permanent magnet flux switching (PMFS) machine is a less common type of PM machines comprising a passive and robust salient-pole rotor and a complex salient-pole stator with armature windings and permanent magnets. The PMFS machine was first introduced as a single phase alternator in 1955 [3], while a three phase machine was first reported in 1997 [4]. More recently there have been renewed research interests in PMFS machines, apparently due to a number of perceived advantages. Since the active parts such as magnets and armature windings are all located on the stator, simple yet effective machine cooling can be easily implemented [5]. Moreover, additional advantages such as rugged rotor structure, high torque density, high efficiency, and good flux-weakening capability, are thoroughly investigated and validated for different applications [6-9]. However, research on the PMFS machine to date has been mainly focused on the general electromagnetic analysis and optimization of the inner-rotor type [10-22] and the linear type [23-27], with hardly any attention given to the outer-rotor PMFS machine. Only recently the outer-rotor PMFS machine has been first proposed for its potential applications in vehicle traction [28], which uses an entirely analytical approach to address the electromagnetic design issues with no experimental validations.

This paper concerns a comprehensive investigation of the outer-rotor configuration of PMFS machine used as an in-wheel drive for light traction applications, with a view to highlighting its projected use in higher power applications. In Section II, the machine geometric topology and the relationships between the stator and rotor pole numbers defining machine phase configuration are introduced, and the preliminary sizing equations of the outer-rotor PMFS machine are developed. In Section III, a three phase outer-rotor PMFS machine with a 12-pole stator is preliminarily designed, and the effects of the rotor pole number on the electromagnetic performance such as back EMF, cogging torque, torque ripples and output torque are studied in depth. Moreover, the optimization of the stator PM thickness and rotor tooth width of the machine with an optimal 22-pole rotor are carried out, and the flux weakening capability of the optimal machine is studied and further improved by segmenting the magnets radially with iron bridges. Section IV is devoted to the FEA estimations of the machine losses such as stator and rotor core losses, PM eddy current losses, and copper losses at different operational conditions, as well as the evaluation of machine efficiency. In Section V, experimental tests are performed on the prototype to 


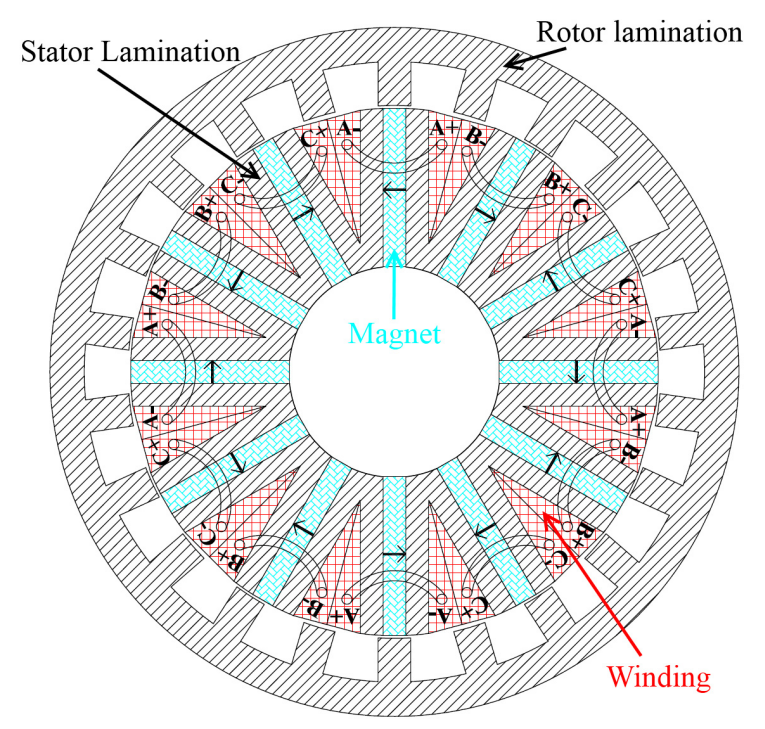

Fig. 1. Cross-section of the three phase outer-rotor 12/22 stator/rotor PMFS machine under study.

validate the FEA results and to confirm the proposed outer-rotor PMFS machine as a viable candidate for in-wheel light traction applications. Section VI provides the concluding remarks.

\section{GeOmetric Topology AND SizING EQUATIONS}

\section{A. Geometric Topology of Outer-Rotor PMFS Machine}

The outer-rotor PMFS machine is a form of doubly salient machine with a novel topology. The concept of flux switching originates from observation that both the amplitude and polarity of the flux linkages in the armature windings change with the rotor position. The cross-sectional view of $12 / 22$ stator/rotor pole three phase outer-rotor PMFS machine under study is shown in Fig.1. Each stator pole consists of two iron teeth and a rectangular PM sandwiched between, and is embraced by a concentrated armature coil, while the rotor pole is simply formed with an iron tooth. The stator pole number $N_{s}$ must be a multiple of the number of phases, and has to be an even number as the PMs in any adjacent poles have the face-to-face polarities. Thus, the stator pole number $N_{s}$ should be a multiple of six in a three phase machine. Moreover, the pole-pair number in such PMFS machines is the same as the rotor pole number $N_{r}$. Consequently, high pole-pair numbers and hence high torque at low speed can be easily facilitated in the proposed outer-rotor PMFS machine. The rotor pole number $N_{r}$ for a three phase machine can be determined by

$$
N_{r}=(12 \pm n) N_{s} / 6
$$

where $n$ is a positive integer which is not a multiple of three. $N_{r}$ is preferred to be even number so that zero resultant radial magnetic force can be achieved.

Fig. 2 is an annotated version of a single rotor-stator pair of the machine, showing the main geometric parameters. In order to increase the winding area and utilize the magnets sufficiently,

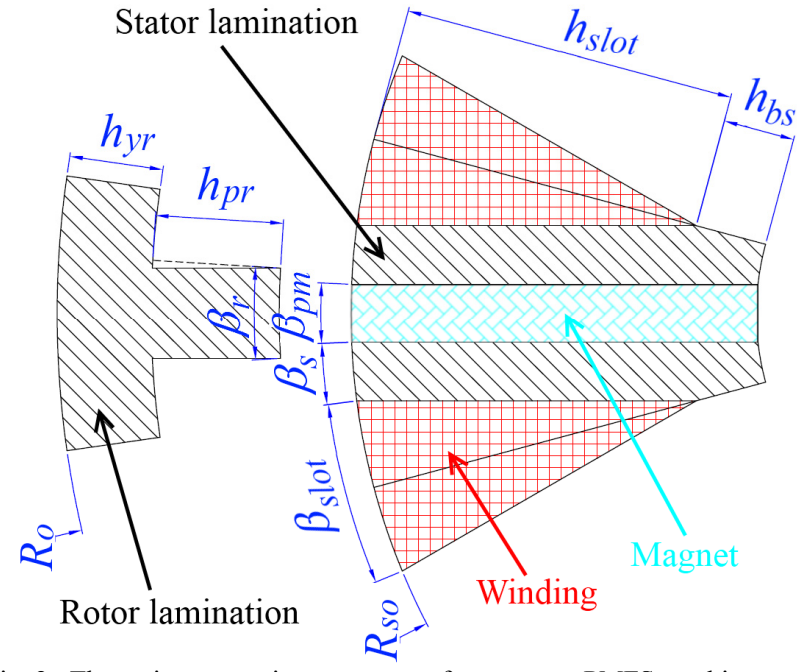

Fig. 2. The main geometric parameters of outer-rotor PMFS machine.

the relationships between the stator tooth arc width $\beta_{s}$, PM arc width $\beta_{p m}$, rotor tooth arc width $\beta_{r}$, and slot opening arc width $\beta_{\text {slot }}$ are initially set as $\beta_{s}=\beta_{p m}=\beta_{r}=\beta_{\text {slot }} / 3$ for the outer-rotor PMFS machine, instead of $\beta_{s}=\beta_{p m}=\beta_{r}=\beta_{\text {slot }}$ commonly employed in a conventional inner-rotor machine.

\section{B. Analytical Sizing Equations}

Analytical sizing equations are of particular importance in the preliminary stages of machine design, as they can be employed to promptly provide the initial values of the machine geometric dimensions from first principles. Hers, $\beta_{s}, \beta_{p m}, \beta_{r}$, $\beta_{\text {slot }}$ can be calculated as

$\beta_{s}=\beta_{p m}=\beta_{r}=\beta_{s l o t} / 3=\pi /\left(3 N_{s}\right)$.

Then, the winding area of one stator slot can be derived as

$A_{w}=R_{s o}^{2} \sin ^{2}\left(\pi /\left(2 N_{s}\right)\right) / \tan \left(\pi / N_{s}\right)$

where $R_{s o}$ is the stator outer radius of the machine. Therefore, the electromagnetic torque $T_{e m}$ can be obtained as

$T_{e m}=\frac{\pi}{16} N_{r} k_{s} k_{l} k_{p} B_{g} J_{p} R_{s o}^{3} l \sin ^{2}\left(\pi /\left(2 N_{s}\right)\right) / \tan \left(\pi / N_{s}\right)$

where $k_{s}, k_{l}$ and $k_{p}$ are the saturation, leakage and winding packing factors respectively, $B_{g}$ is the peak air gap flux density at no load condition, $J_{p}$ is the peak value of rated current density in the coils, and $l$ is the active length of the machine. The flux leakages in the outer-rotor PMFS machine are far more significant compared with that of the inner-rotor one due to its relatively large slot opening. It can be observed that the torque output of the machine is approximately proportional to the cube of $R_{s o}$. In addition, the rotor pole height $h_{p r}$ is set at one-sixth of the stator outer radius $R_{s o}$ to achieve sufficient rotor saliency, and the rotor yoke thickness $h_{y r}$ is chosen to be 1.5 times the stator back iron thickness $h_{b s}$ in order to alleviate 
potential mechanical vibration. Hence, the rotor outer radius can be expressed as

$$
R_{o}=\left(7 / 6+\pi /\left(2 N_{s}\right)\right) R_{s o}+g
$$

where $g$ is the air gap length of the machine. With the required torque output $T_{e m}$ and other constraints, the machine's key dimensions can be pre-determined from formulae (4) and (5).

\section{Machine Design And Optimizations}

Based on the aforementioned sizing equations, an outer-rotor PMFS machine with a 12-pole stator is intially chosen, with the designed values of the key parameters given in Table I. As the rated rotational speed of the machine is quite low at $120 \mathrm{rpm}$, $0.50 \mathrm{~mm}$ lamination sheets of silicon steel type 50ww600 are chosen for the stator and rotor cores, and high strength rare earth neodymium-iron-boron $(\mathrm{NdFe} 35)$ magnets are used to achieve high torque density. Each coil in the stator consists of 8 turns of 11-stranded copper wires with $0.70 \mathrm{~mm}$ diameter, and the four armature coils in each phase are connected in series. Therefore, a moderate winding package factor of $42 \%$ has been achieved. It is noteworthy that the proposed machine, while designed as a low voltage drive suitable for light traction, is also intended to validate the concept of the outer-rotor PMFS machine for more general in-wheel traction applications.

TABLE I

MAIN DESIGN PARAMETERS OF THE INITIAL MACHINE

\begin{tabular}{cccc}
\hline \hline Symbol & Machine Parameter & Values & Unit \\
\hline$p$ & Phase number & 3 & - \\
$N_{s}$ & Stator pole number & 12 & - \\
$N$ & Coil turn number & 8 & - \\
$\mathrm{PM}$ & Permanent magnet material & NdFeB35 & - \\
- & Stator and rotor lamination & 50 ww600 & - \\
$R_{s o}$ & Stator outer radius & 50 & $\mathrm{~mm}$ \\
$R_{o}$ & Rotor outer radius & 65.3 & $\mathrm{~mm}$ \\
$g$ & Air gap length & 0.40 & $\mathrm{~mm}$ \\
$\beta_{s}$ & Stator tooth arc width & 5 & degree \\
$\beta_{p m}$ & Permanent magnet arc width & 5 & degree \\
$\beta_{r}$ & Rotor tooth arc width & 5 & degree \\
$h_{y r}$ & Rotor yoke thickness & 6.6 & $\mathrm{~mm}$ \\
$h_{p r}$ & Rotor tooth height & 8.3 & $\mathrm{~mm}$ \\
$h_{b s}$ & Stator back iron thickness & 4.4 & $\mathrm{~mm}$ \\
$k_{p}$ & Winding package factor & $42 \%$ & - \\
$J_{p}$ & Rated current density & $5.0(\mathrm{peak})$ & $\mathrm{A} / \mathrm{mm}$ \\
$l$ & Machine stack length & 60 & $\mathrm{~mm}$ \\
$n_{r}$ & Rated rotational speed & 120 & $\mathrm{rpm}$ \\
$U_{d c}$ & DC link voltage & 12 & $\mathrm{~V}$ \\
$I_{r}$ & Rated phase current & $25(\mathrm{peak})$ & $\mathrm{A}$ \\
\hline \hline
\end{tabular}

\section{A. Rotor Pole Number Optimization}

For conventional three phase inner-rotor PMFS machine, the rotor pole number $N_{r}$ is usually designed as close to the stator pole number $N_{s}$ to maximize the machine performance [18]. However, the geometric configuration in outer-rotor machine would make larger $N_{r}$ more preferable. On the other hand, the cogging torque is of particular importance for in-wheel traction applications due to the absence of the gears and existance of the adverse effects. The number of cogging torque periods per rotor revolution is given by the least common multiple of $N_{s}$
TABLE II

DifFerent Rotor POLE NuMBERS FOR OUTER-ROTOR THREe PHASE PMFS MACHINE WITH TWELVE STATOR POLES

\begin{tabular}{cccccc}
\hline \hline$N_{r}\left(N_{s}=12\right)$ & 14 & 16 & 20 & 22 & 26 \\
\hline$L C M\left(N_{s}, N_{r}\right)$ & 84 & 48 & 60 & 132 & 156 \\
$G C D\left(N_{s}, N_{r}\right)$ & 2 & 4 & 4 & 2 & 2 \\
\hline \hline
\end{tabular}

TABLE III

IMPACTS OF ROTOR POLE NUMBER ON CHARACTERISTICS OF OUTER-ROTOR THREE PHASE PMFS MACHINE WITH TWELVE STATOR POLES

\begin{tabular}{cccccc}
\hline \hline$N_{r}$ & $\begin{array}{c}\text { Fundamental } \\
\text { back EMF } \\
\text { harmonic }\end{array}$ & $\begin{array}{c}2^{\text {nd }} \text { back } \\
\text { EMF } \\
\text { harmonic }\end{array}$ & $\begin{array}{c}\text { Cogging } \\
\text { toque } \\
(\mathrm{P}-\mathrm{P})\end{array}$ & $\begin{array}{c}\text { Rated } \\
\text { average } \\
\text { torque }\end{array}$ & $\begin{array}{c}\text { Torque } \\
\text { ripple } \\
(\mathrm{P}-\mathrm{P})\end{array}$ \\
\hline 14 & $2.150 \mathrm{~V}$ & $0.000 \mathrm{~V}$ & $7.52 \mathrm{~N} \cdot \mathrm{m}$ & $6.30 \mathrm{~N} \cdot \mathrm{m}$ & $6.98 \mathrm{~N} \cdot \mathrm{m}$ \\
16 & $2.010 \mathrm{~V}$ & $0.127 \mathrm{~V}$ & $8.20 \mathrm{~N} \cdot \mathrm{m}$ & $5.92 \mathrm{~N} \cdot \mathrm{m}$ & $8.17 \mathrm{~N} \cdot \mathrm{m}$ \\
20 & $1.910 \mathrm{~V}$ & $0.030 \mathrm{~V}$ & $8.71 \mathrm{~N} \cdot \mathrm{m}$ & $5.73 \mathrm{~N} \cdot \mathrm{m}$ & $9.03 \mathrm{~N} \cdot \mathrm{m}$ \\
22 & $2.530 \mathrm{~V}$ & $0.000 \mathrm{~V}$ & $0.79 \mathrm{~N} \cdot \mathrm{m}$ & $7.47 \mathrm{~N} \cdot \mathrm{m}$ & $1.49 \mathrm{~N} \cdot \mathrm{m}$ \\
26 & $2.169 \mathrm{~V}$ & $0.000 \mathrm{~V}$ & $1.38 \mathrm{~N} \cdot \mathrm{m}$ & $6.30 \mathrm{~N} \cdot \mathrm{m}$ & $0.91 \mathrm{~N} \cdot \mathrm{m}$ \\
\hline \hline
\end{tabular}

and $N_{r}, \operatorname{LCM}\left(N_{s}, N_{r}\right)$. Also, cogging torque amplitude is usually proportional to the greatest common divisor of $N_{s}$ and $N_{r}$, $G C D\left(N_{s}, N_{r}\right)$. Hence, it is often recommended to effectively mitigate cogging torque by selecting a high $\operatorname{LCM}\left(N_{s}, N_{r}\right)$ and a low $G C D\left(N_{s}, N_{r}\right)$.

Various rotor pole numbers for the three phase outer-rotor PMFS machine with a 12-pole stator according to equation (1), as given in Table II, have been investigated and compared, in order to determine the optimal. During the analysis, the parameters in Table I are all kept as invariables. Two-dimensional (2-D) FEA simulations of the machines with different rotor pole numbers are performed in no and full load conditions. The amplitudes of fundamental and second harmonics of phase back EMF, as well as peak-to-peak (P-P) cogging torque values, which are obtained from the FEA models with no load condition, are shown in Table III. It can be seen that the machine with 22 rotor poles exhibits the highest fundamental component of phase back EMF while the machine with 20 rotor poles has the lowest. The even harmonics, in particular the second one, are very evident in the phase back EMF of the machines with 16 and 20 rotor poles due to their asymmetric magnetic structures. Additionally, the extents of cogging torque are prominent in the machines with 14,16 , and 20 rotor poles, and relatively diminutive in the ones with 22 and 26 rotor poles. On the whole, the machine with 22 rotor poles enjoys the lowest cogging torque. Furthermore, both the average values of the torque and P-P values of the torque ripple of the machines under the full load condition are derived, and are included as well in Table III. It can be found that the highest torque is produced in the machine with 22 rotor poles. The average rated torque of the machines, by and large, follows the same trend of the fundamental back EMF. Together with equation (4), it can be inferred that $N_{r}$ has considerable impacts on $k_{s}$ and $k_{l}$, and hence the machine with large $N_{r}$ would not necessarily deliver high torque. The P-P values of the torque ripple in the machines with 14,16 , and 20 rotor poles are strikingly large as the cogging torque is the dominant component of the overall torque ripple in these machines. The $\mathrm{P}-\mathrm{P}$ torque ripple value for the machine with 22 rotor poles is almost double that of the cogging torque as a result of the 


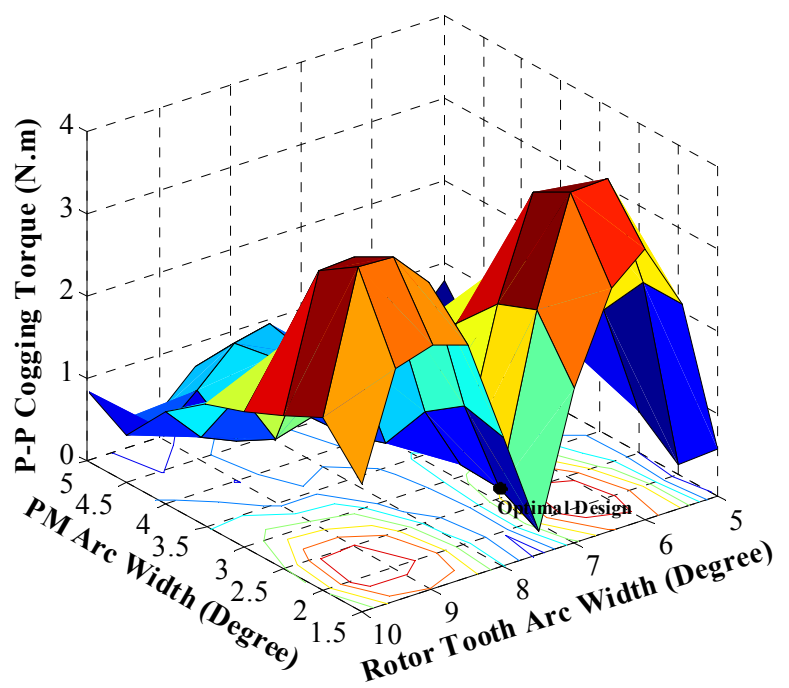

Fig. 3. P-P cogging torque variations with different rotor tooth arc widths and PM arc widths.

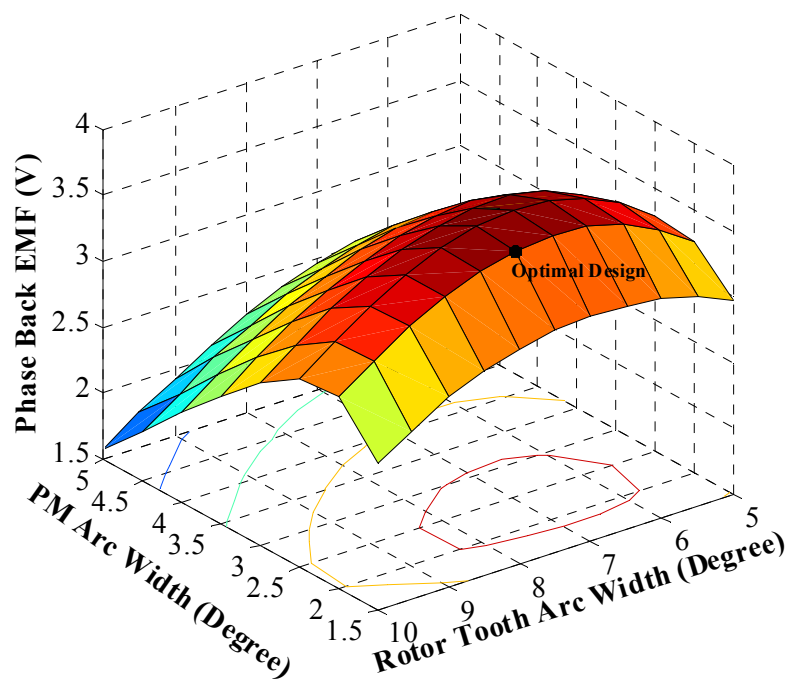

Fig. 4. Fundamental phase back EMF variations with different rotor tooth arc widths and PM arc widths.

aggravated load-dependent torque pulsation. On the contrary, the cogging torque is partially counteracted by the load-dependent torque pulsation for the machine with 26 rotor poles, resulting in the smallest overall torque ripple. From the preceding analysis, it becomes clear that the rotor pole number has great influence on the performance of the outer-rotor PMFS machine. Taking all relevant factors into consideration, the machine with 22 rotor poles proves to be the optimal design and is selected for the study hereinafter.

\section{B. PM and Rotor Tooth Arc Width Optimizations}

The original geometric dimensions in equation (2) are assigned for the initial design and hence are not necessarily optimal. Moreover, the optimal values of those parameters are highly interdependent. Thus, multi-parameter optimizations are considered necessary. In this subsection, the synthetic optimizations of the rotor tooth arc width $\beta_{r}$ and PM arc width $\beta_{p m}$ together are carried out by 2-D FEA. During the

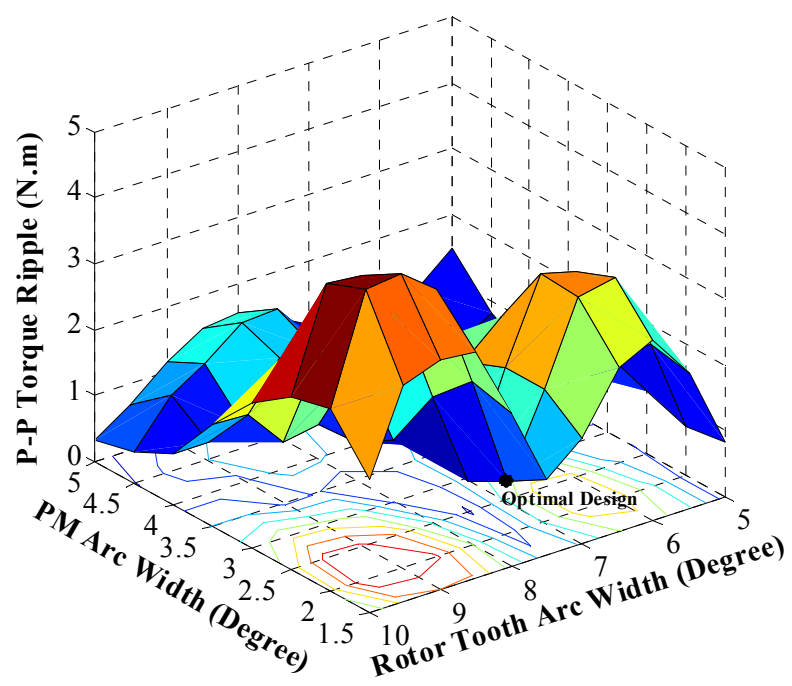

Fig. 5. P-P torque ripple variations with different rotor tooth arc widths and $\mathrm{PM}$ arc widths.

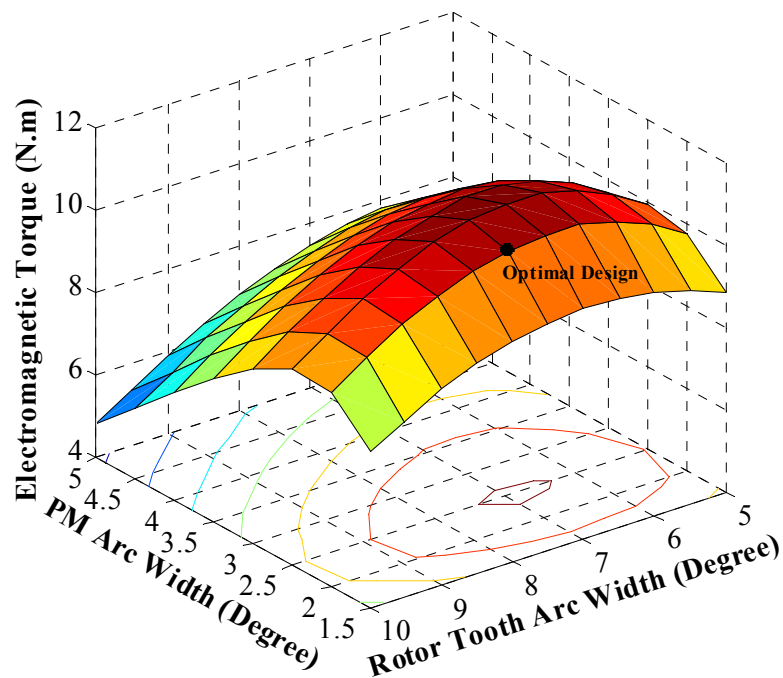

Fig. 6. Electromagnetic torque variations with different rotor tooth arc widths and PM arc widths.

optimization, the stator pole arc width $\theta_{s}\left(2 \beta_{s}+\beta_{p m}\right)$ is fixed as 15 degrees to keep the windings unchanged.

Based on 2-D FEA, the cogging torque and phase back EMF of the machine can be directly derived from the open-circuit field analysis. The P-P cogging torque and fundamental phase back EMF values of the machines with different $\beta_{r}$ and $\beta_{p m}$ are plotted in Fig. 3 and Fig. 4 respectively. Fig. 3 reveals that both $\beta_{r}$ and $\beta_{p m}$ have significant impacts on the cogging torque of the machine. The cogging torque can be substantially suppressed as $\beta_{r}$ is close to 5 degrees or 7.5 degrees, and large values of $\beta_{p m}$ would generally produce relatively low cogging torque. It can also be found from Fig. 4 that the phase back EMF of the machine is greatly influenced by $\beta_{r}$ and $\beta_{p m}$. With different $\beta_{r}$, the optimal $\beta_{p m}$ for maximum phase back EMF is nearly constant at 2.5 degrees, while with different $\beta_{p m}$, the optimal $\beta_{r}$. for maximum phase back EMF is also unchanged at as 7 degrees. Consequently, the machine with 2.5 degrees PM arc 


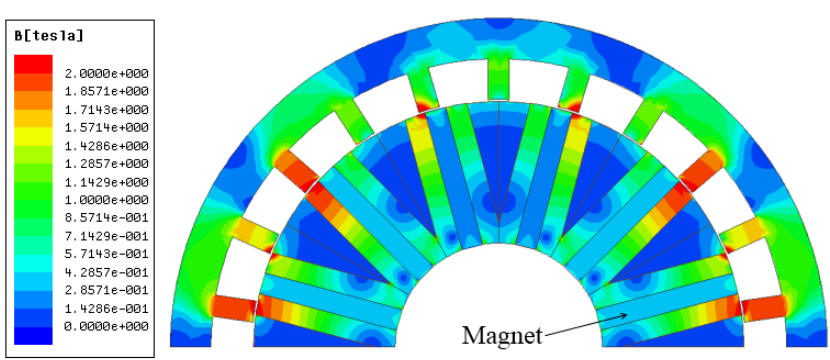

(a)

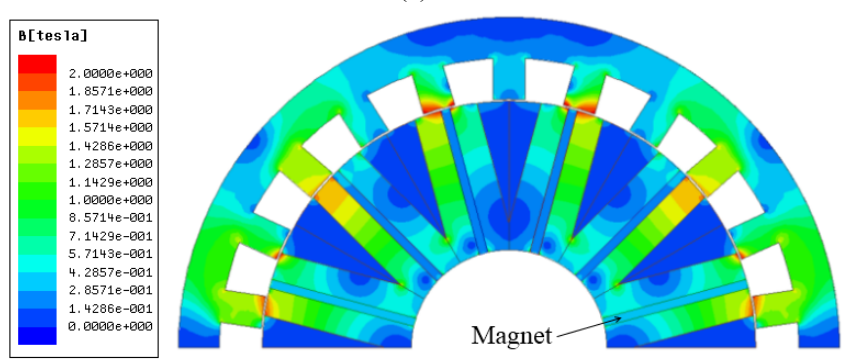

(b)
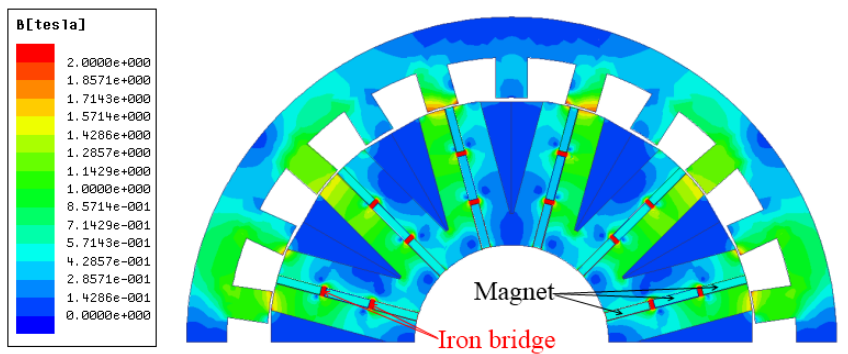

(c)

Fig. 7. The flux density distribution of the machines from 2-D FEA results, (a) original design, (b) optimal design, (c) final design.

TABLE IV

TORQUE AND BACK EMF CHARACTERISTICS OF THE THREE MACHINES

\begin{tabular}{ccccc}
\hline \hline Machines & $\begin{array}{c}\text { Cogging } \\
\text { torque } \\
(\mathrm{P}-\mathrm{P})\end{array}$ & $\begin{array}{c}\text { Fundamental } \\
\text { back EMF } \\
\text { Harmonic }\end{array}$ & $\begin{array}{c}\text { Torque } \\
\text { ripple } \\
(\mathrm{P}-\mathrm{P})\end{array}$ & $\begin{array}{c}\text { Rated } \\
\text { average } \\
\text { torque }\end{array}$ \\
\hline Original design & $0.79 \mathrm{~N} \cdot \mathrm{m}$ & $2.530 \mathrm{~V}$ & $1.49 \mathrm{~N} \cdot \mathrm{m}$ & $7.47 \mathrm{~N} \cdot \mathrm{m}$ \\
Optimal design & $0.54 \mathrm{~N} \cdot \mathrm{m}$ & $3.621 \mathrm{~V}$ & $0.78 \mathrm{~N} \cdot \mathrm{m}$ & $10.76 \mathrm{~N} \cdot \mathrm{m}$ \\
Final design & $0.46 \mathrm{~N} \cdot \mathrm{m}$ & $3.201 \mathrm{~V}$ & $0.65 \mathrm{~N} \cdot \mathrm{m}$ & $9.24 \mathrm{~N} \cdot \mathrm{m}$ \\
\hline \hline
\end{tabular}

TABLE V

FLUX-WEAKENING CAPABILITY COMPARISONS OF THE THREE MACHINES

\begin{tabular}{cccc}
\hline \hline Parameters & Original Design & Optimal Design & Final Design \\
\hline$\psi_{p m}$ & $9.15 \mathrm{mWb}$ & $13.10 \mathrm{mWb}$ & $11.58 \mathrm{mWb}$ \\
$L_{d}$ & $101.42 \mu \mathrm{H}$ & $298.91 \mu \mathrm{H}$ & $293.28 \mu \mathrm{H}$ \\
$L_{q}$ & $110.57 \mu \mathrm{H}$ & $256.52 \mu \mathrm{H}$ & $316.63 \mu \mathrm{H}$ \\
$\omega_{\max }$ & $47.61 \mathrm{rad} / \mathrm{s}$ & $55.96 \mathrm{rad} / \mathrm{s}$ & $74.13 \mathrm{rad} / \mathrm{s}$ \\
$\beta$ & 1.383 & 2.328 & 2.726 \\
\hline \hline
\end{tabular}

width and 7 degrees rotor tooth arc width would generate the highest fundamental phase back EMF value. Furthermore, the torque ripple and output torque of the machine with rated armature current excitation are estimated and shown in Fig. 5 and Fig. 6 respectively. The P-P torque ripple variations in Fig.5 resemble the P-P cogging torque ones in Fig. 3 as the cogging torque is one of the major contributors of the overall torque ripple in the machine. In general, relatively small values of $\beta_{p m}$, with $\beta_{r}$ being 5 or 7.5 degrees, can effectively mitigate the torque ripple of the proposed machine. Similarly, the average electromagnetic torque variations in Fig. 6 follow a very similar profile of the fundamental phase back EMF in Fig. 4. As $\beta_{p m}$ exceeds 2.5 degrees, magnetic saturations occurring in the stator laminations are getting increasingly severe and hence the rated average torque of the machine deteriorates considerably. The largest rated average torque is achieved for the machine with $\beta_{p m}$ at 2.5 degrees and $\beta_{r}$ at 7 degrees.

Based on the preceding analysis, the machine with $\beta_{p m}$ at 2 degrees and $\beta_{r}$ at 7.5 degrees, as marked in Fig.3, 4, 5 and 6, is chosen as the optimal design in terms of overall torque output and torque ripple performance. The flux density distributions of the machine with original and optimal designs from 2-D FEA results are shown in Fig. 7 (a) and (b) respectively. It can be seen that both the stator and rotor poles are much more severely saturated in the original design than the optimal one. The corresponding torque and back EMF characteristics of the machine with the two designs are given in Table IV, which clearly shows that the cogging torque and torque ripple are reduced by $31.6 \%$ and $47.6 \%$ respectively while the rated average torque is substantially improved by $44 \%$ in the optimal design.

\section{Flux-Weakening Capability}

The flux-weakening capability is of particular importance for in-wheel light traction applications. As the machine operates above the base speed, the back EMF induced by constant PM flux would exceed the inverter supply voltage so that no current can be fed into the machine. In order to achieve beyond based speed operations with constant power output, flux-weakening control can be implemented by adjusting the phase angle of the armature current. The maximum speed which the machine can reach under flux-weakening operation with space vector pulse width modulation can be expressed as

$\omega_{\max }=U_{d c} /\left(\sqrt{3} N_{r}\left(\psi_{p m}-L_{d} I_{r}\right)\right)$

where $\psi_{p m}$ and $L_{d}$ are the phase PM flux linkage and $d$-axis inductance of the machine, and $I_{r}$ is the peak value of rated phase current. Moreover, the speed extension ratio $\beta$ can be defined to quantify the flux-weakening capability of the proposed outer-rotor PMFS machine as

$\beta=\psi_{p m} /\left(\psi_{p m}-L_{d} I_{r}\right)$

The flux-weakening capability of the machine can be enhanced effectively by either improving $L_{d}$ or abating $\psi_{p m}$. Additionally, the machine's torque output can be derived by

$T_{e m}=3 N_{r}\left(2 \psi_{p m} I_{r} \cos (\varphi)-\left(L_{d}-L_{q}\right) I_{r}^{2} \sin (2 \varphi)\right) / 4$

where $\varphi$ is the phase angle by which the current vector leads the rotor $q$-axis, and $L_{q}$ is the $q$-axis inductance. It can be inferred 


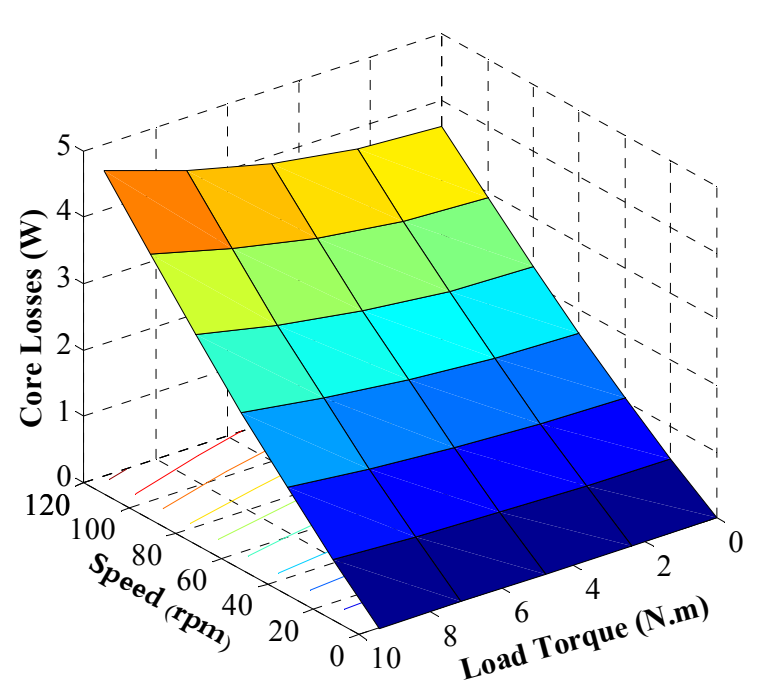

Fig. 8. Estimated core losses in the stator and rotor laminations of the final design for different speed and load torque conditions.

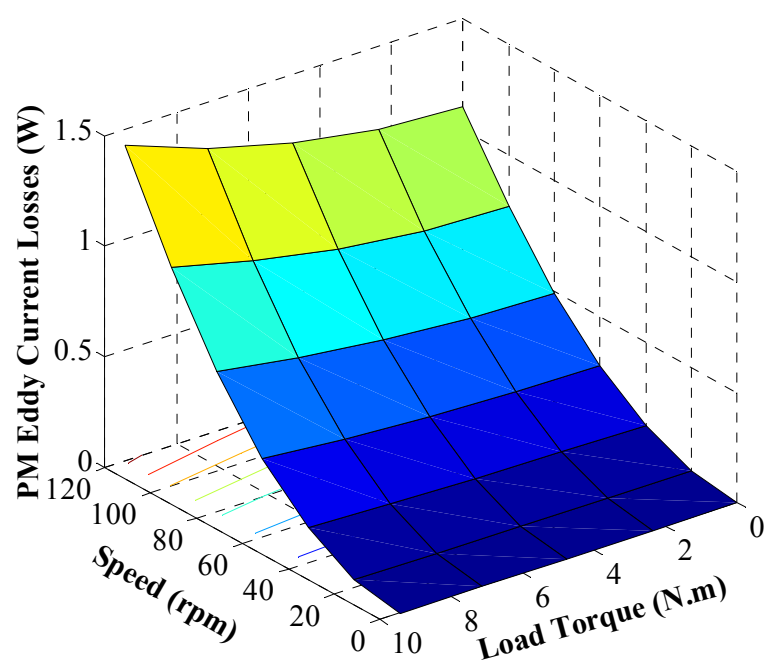

Fig. 9. Estimated eddy current losses in the permanent magnets of the final design for different speed and load torque conditions.

form (8) that making $L_{d}<L_{q}$ is a preferred way to harness the reluctance torque during the flux-weakening operation.

Small portions of the PM can be canalized into iron sections to effectively improve the flux-weakening capability in interior permanent magnet machine $[29,30]$. In such a way, the PM flux linkages can be effectively reduced. The final design thus involves the PMs in the stator of the optimal design being radially segmented into three equal pieces by two iron bridges with a width of $1 \mathrm{~mm}$ to promote the flux-weakening capability. Severe magnetic saturation in the iron bridges, which is evident in the flux density distribution of the final design in Fig. 7 (c), eventually results in a reduction of the $d$-axis flux linkage or inductance at high current. The torque and back EMF characteristics of the design are given in Table IV, which show both the cogging torque and torque ripple are further reduced by $14.8 \%$ and $16.7 \%$ respectively at the expense of $11.6 \%$ and $14.1 \%$ drops in the fundamental back EMF and rated average torque respectively. Moreover, the PM flux linkages, $d$ - and

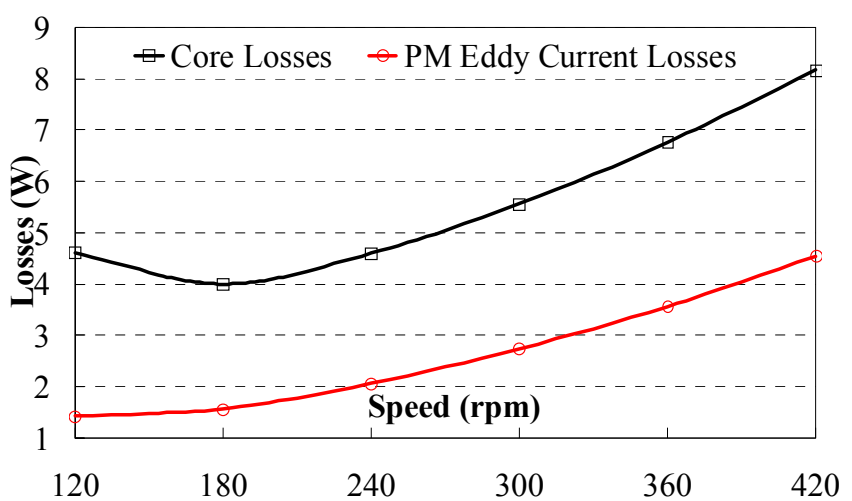

Fig. 10. Estimated core losses and PM eddy current losses of the final design for different speed under flux-weakening operation with constant power.

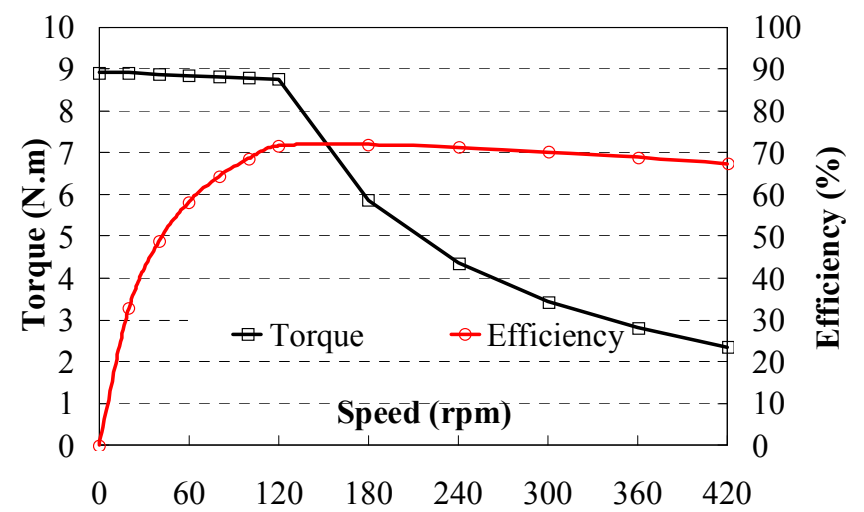

Fig. 11. Estimated torque output and corresponding efficiency of the final design for different speed with rated current excitation.

$q$-axis inductances of the three designs from 2-D FEA, as well as the corresponding maximum achievable speeds and speed extension ratios, are all given and compared in Table $\mathrm{V}$, which confirms that the final design has the best flux-weakening capability. Compared with the optimal design, the final one has a descendent PM flux linkage but almost maintains the same $d$-axis inductance. Most importantly, making $L_{d}>L_{q}$ in the optimal design would generate negative reluctance torque during the flux-weakening operation, while with $L_{d}<L_{q}$ in the final one would produce positive one instead and hence further improve the flux-weakening capability. It is worth mentioning that eddy current losses in the PMs are likely to be significantly reduced in the final design due to the segmentation.

\section{Machine Losses ANd EFFICIENCY ANALYSIS}

Machine losses are a complex function of the speed and load. However, electromagnetic losses dominate total losses in low-speed machines. Thus, the analysis here will only focus on these losses. Electromagnetic losses can be generally broken down into three distinct parts, copper resistive losses in the coils, core losses in the stator and rotor laminations, and eddy current losses in the PMs. The copper resistive losses can be simply determined from the estimated phase resistance and the torque-current profile of the machine from the 2-D FEA results. The predicted resistance of one phase at $80^{\circ} \mathrm{C}$ is $40 \mathrm{~m} \Omega$, and the corresponding copper resistive loss at rated current excitation is found to be $37.5 \mathrm{~W}$. 


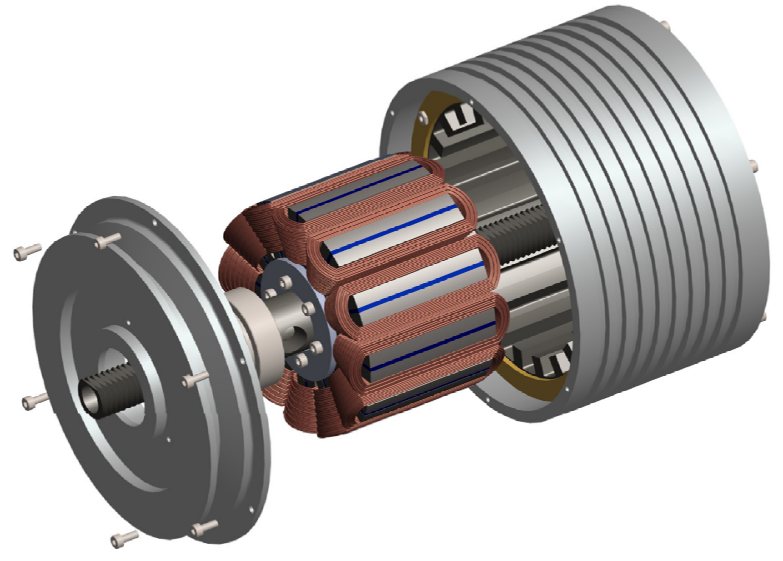

(a)

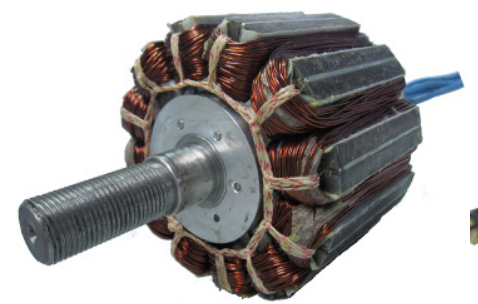

(b)

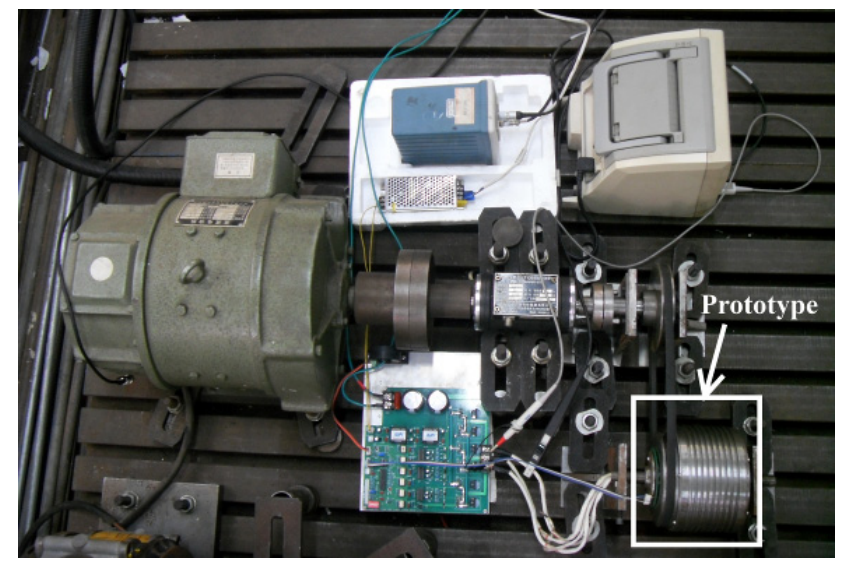

(d)

Fig.12 Prototype machine and experimental validation (a) Exploded view (b) Wound stator (c) Assembled machine, (d) Experimental setup.

Transient 2-D FEA can be employed to calculate the core losses in electrical steel laminations and eddy current losses in the PMs considering the harmonics, and the estimated results of the final design for different speed and load torque conditions are depicted in Fig. 8 and Fig. 9 respectively. From Fig.8, the core losses in the laminations are fairly small due to the low operational speed, and the load torque has negligible impact. The PM eddy current losses are significantly suppressed by segmentation, and can be negligible as shown in Fig.9. Furthermore, the losses in the final design under flux weakening operations are evaluated, and with $37.5 \mathrm{~W}$ copper resistive loss, the corresponding core and PM eddy current losses under the extended speeds are shown in Fig.10. As the speed rises, the core losses first drop slightly then increase significantly while the PM eddy current losses gradually grow. The efficiency of the final design with rated current excitation, together with the corresponding torque output, are shown in Fig.

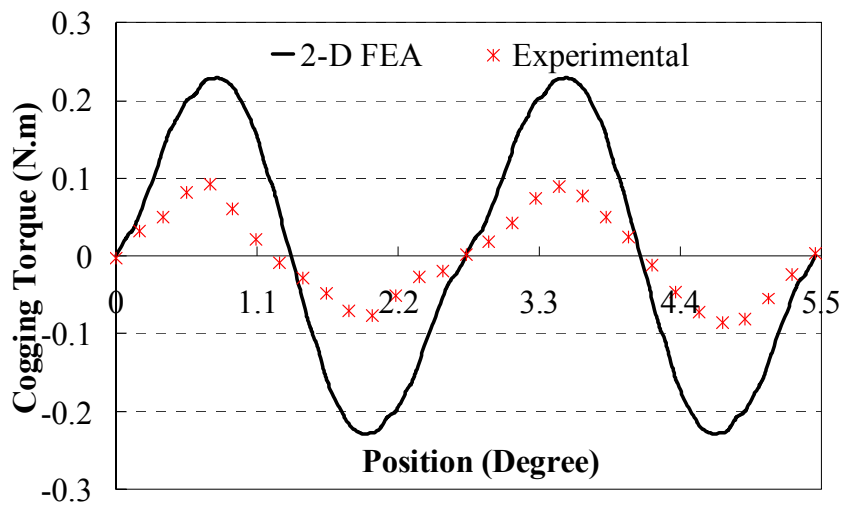

Fig. 13. Cogging torque profiles of the prototype machine from 2-D FEA estimation and experimental measurement.

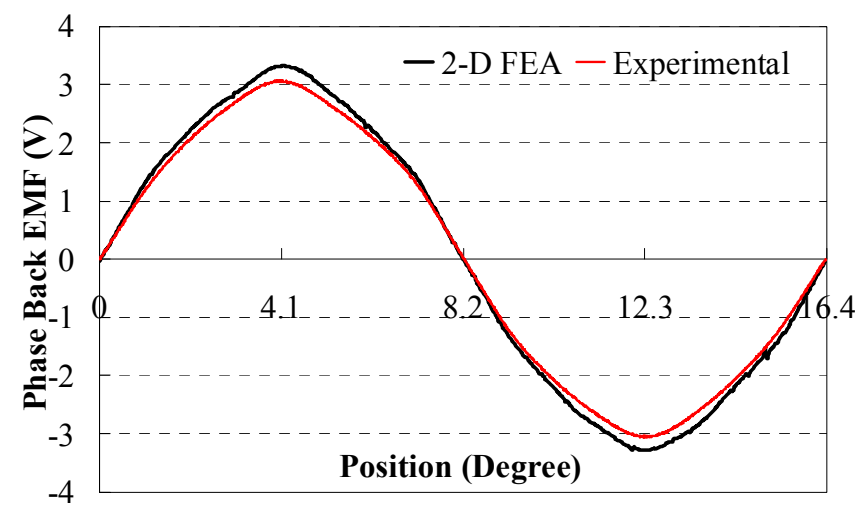

Fig. 14. Phase back EMF waveforms of the prototype machine from 2-D FEA estimation and experimental measurement.

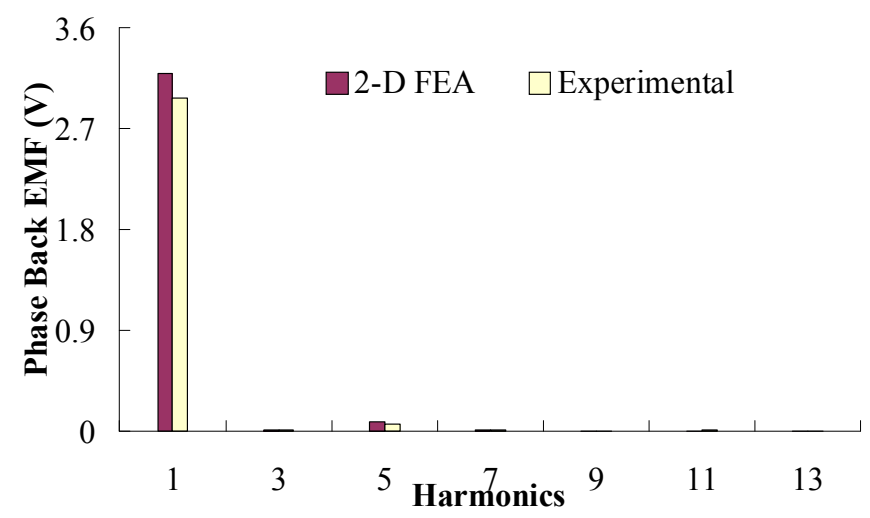

Fig. 15. Harmonic spectrum of the phase back EMF of the prototype machine from 2-D FEA estimation and experimental measurement.

11, which shows the efficiency of the machine just drops slightly as the speed increases, and maintains above $67.3 \%$ under flux weakening operation region. Considering the relatively low power output, the efficiency curve confirms the proposed outer-rotor PMFS machine as a potential contender for in-wheel light traction applications.

\section{EXPERIMENTAL VALIDATIONS AND DISCUSSIONS}

The machine of the final design in Fig.7(c) is prototyped for experimental validations. Fig. 12 shows the prototype machine and the setup used for the machine tests. The motor is driven by a BLAC control strategy with space vector pulse width modulation. For the load tests, the motor is powered by a $12 \mathrm{~V}$ 


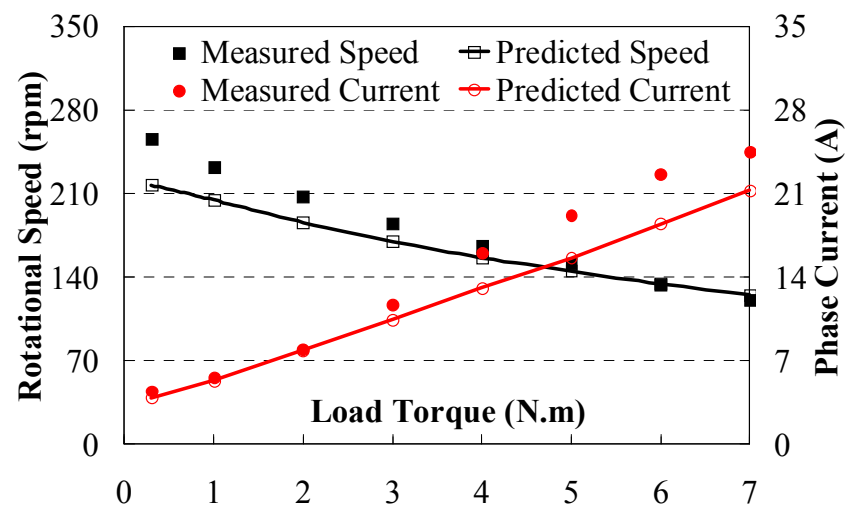

Fig. 16. Machine speed and phase current profiles against torque load @ 12V DC link voltage..

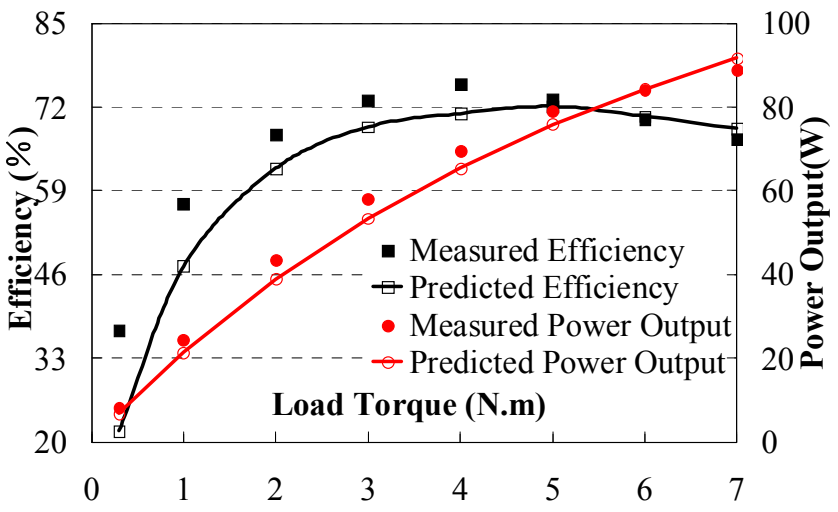

Fig. 17. Machine efficiency and power output profiles against torque load @ $12 \mathrm{~V}$ DC link voltage.

DC link. The reason to use a relatively low supply voltage is to resemble that of a battery powered light vehicle. Another main reason is to ensure the main objective of the investigation is not hampered by unduly experimental complications of driving the motor at higher loads, when results at the lower voltage not only demonstrate the viability of the drive, but also provide a reliable baseline for extrapolated performance of the machine.

\section{A. Open Circuit Tests}

The predicted cogging torque profile from the 2-D FEA model and the experimental result is compared in Fig. 13, which shows that the predicted peak value is more than two times higher than the measured value. The deviation underlines the practical difficulty of accurate measurement of the relatively small value of cogging torque on the one hand, and the sensitivity of cogging torque to manufacture tolerances and deficiencies on the other. Moreover, the 2-D FE analysis does not account for three-dimensional (3-D) effects such as flux fringing in the machine. Nonetheless, the predicted and measured waveforms show that they follow essentially the same variation. The corresponding back EMFs of the machine measured at rated speed is shown in Fig.14, and the corresponding harmonic contents in Fig.15. Generally the back EMF is relatively less sensitive to mechanical defects and bench measurements than in the case of low level cogging torque, the fundamental phase back EMF from the experiment is about $7.0 \%$ lower than the one from estimated one. Taking into account the 3-D flux leakage effects and lamination stack

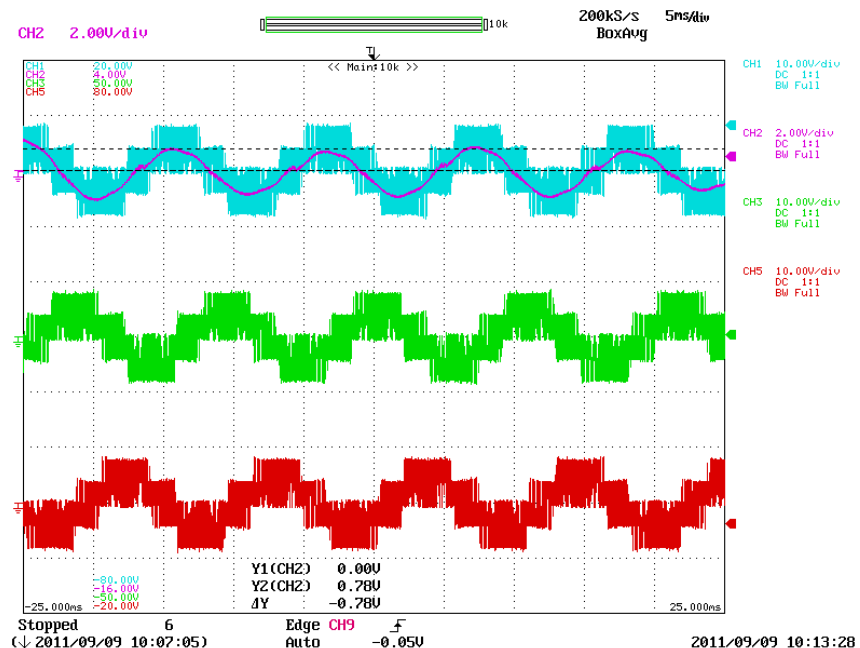

(a)

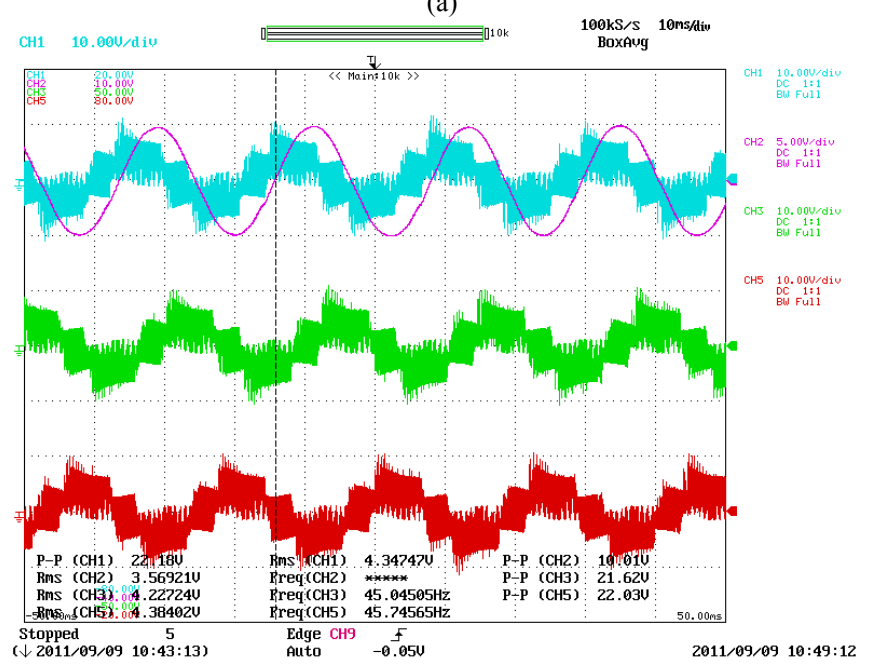

(b)

Fig. 18. The measured phase voltage and current waveforms at no load and rated load conditions, (a) no load condition, (b) rated load condition (25A). (CH1 - Phase A voltage, $\mathrm{CH} 3$ - Phase B voltage, $\mathrm{CH} 5$ - Phase $\mathrm{C}$ voltage, $\mathrm{CH} 2$ - Phase A current.)

factor, it is fair to state there are very close agreements between the experimental and predicted results. Additionally, the measured phase resistance at room temperature is about $30 \mathrm{~m} \Omega$, which is slightly higher than the estimated one, while the measured $d$ - and $q$-axis inductances are $321.7 \mu \mathrm{H}$ and $375.3 \mu \mathrm{H}$ respectively, which are much higher than the estimated ones from 2-D FEA mainly due to the effects of the machine end regions.

\section{B. On Load Tests}

The tested speed and phase current profiles against different torque loads at $12 \mathrm{~V}$ DC link voltage are given and compared with the predicted ones in Fig.16, whereas the corresponding estimated and measured machine efficiency and power output are demonstrated in Fig.17. It is noted from Fig.16 that predicted machine speed at light load is much lower than the measured one as a result of the overestimated machine phase back EMF seen from Fig. 14. However, both the measured currents and machine inductances are higher than the predicted ones, therefore the measured speed declines faster than the predicted one as the load of the machine increases as depicted. 


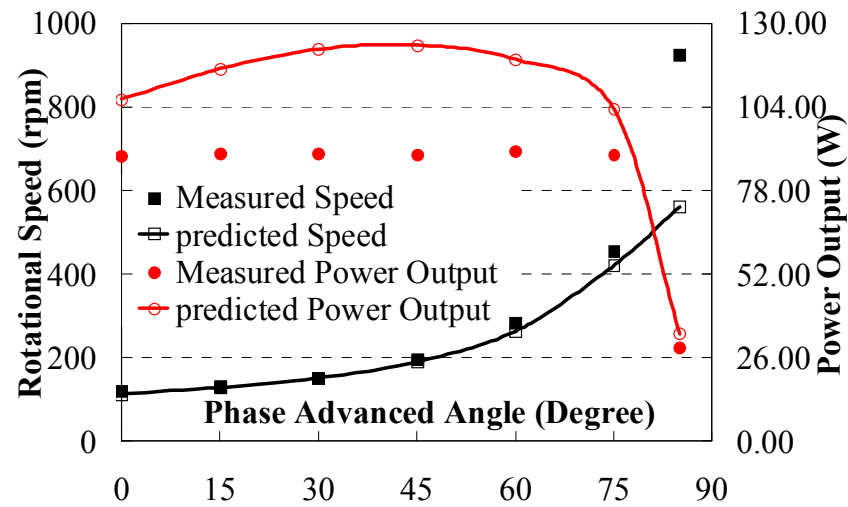

Fig. 19. Machine speed and Power output profiles with different current phase advanced angle from the experimental tests with $12 \mathrm{~V}$ DC link voltage and $25 \mathrm{~A}$ phase current.

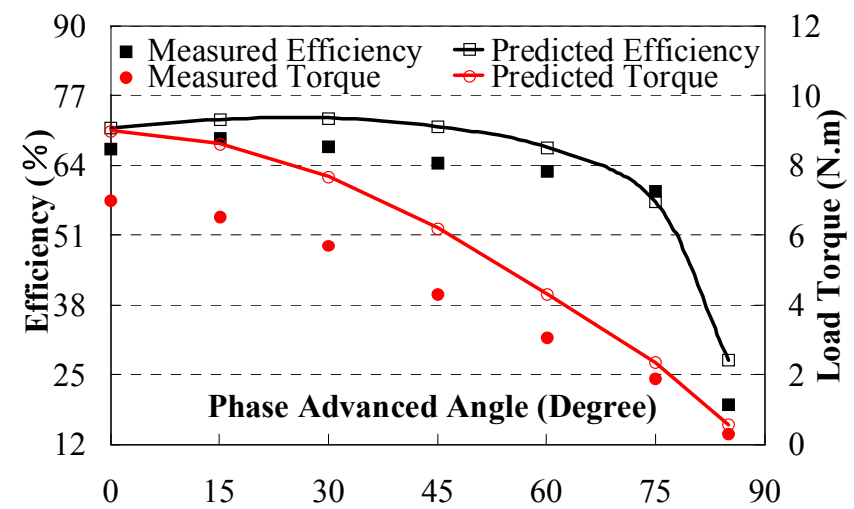

Fig. 20. Machine efficiency and torque profiles with different current phase advanced angle from the experimental tests with $12 \mathrm{~V}$ DC link voltage and $25 \mathrm{~A}$ phase current.

On the other hand, the measured phase current under high load condition is much higher the estimated one due to the lower measured phase back EMF and higher inductances. Due to the higher measured speed, the measured power output of the machine is higher than the predicted ones except the ones with the load above $6 \mathrm{~N} \cdot \mathrm{m}$. Accordingly, the efficiency of the machine from the tested results is higher under light load condition and gradually turns into lower than estimated one as the load increases due to higher measured current hence resistive losses. Furthermore, the results show that the machine achieves an efficiency of $67 \%$ under full load condition of $7 \mathrm{~N}$.m, and the maximum of $75 \%$ under load condition of about $47 \mathrm{~N}$.m. In addition, the mechanical transmission in the testing setup, as shown in Fig.12(d), would engender considerable friction losses hence contribute extra errors in the experimental results. Taking all these factors into considerations, it is fair to state that profiles curve from the experiment is in broad agreements with the 2-D FEA predicted ones. Furthermore, the waveforms of the three phase voltage together with one phase current from experimental load tests are depicted as Fig. 18, one under no load condition shown in Fig. 18(a), and another full load condition shown in Fig. 18(b).

\section{Flux-Weakening Capability Tests}

The flux-weakening capability of the prototype is tested under the loading condition of $12 \mathrm{~V}$ DC link voltage and $25 \mathrm{~A}$ phase current over a range of advanced firing angle. The

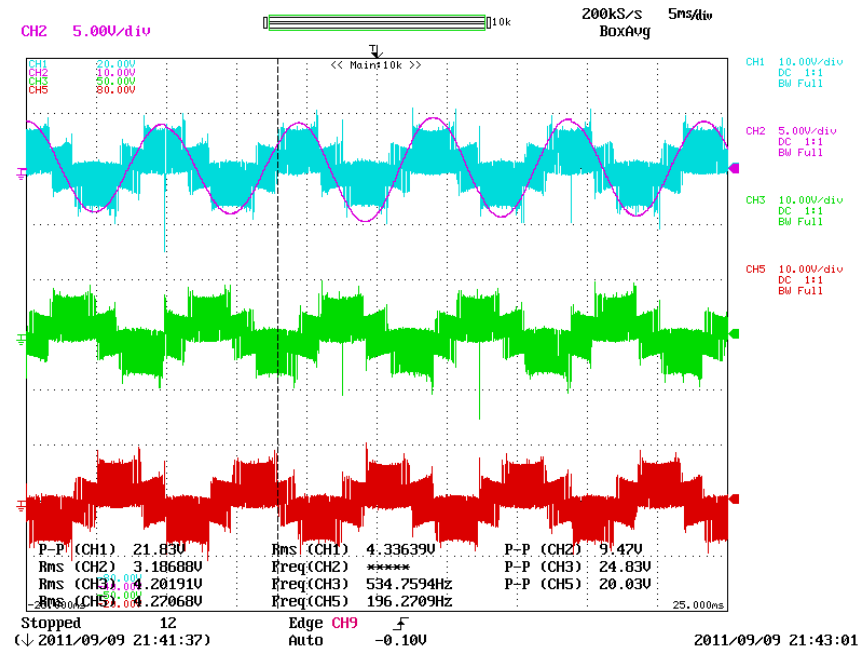

(a)

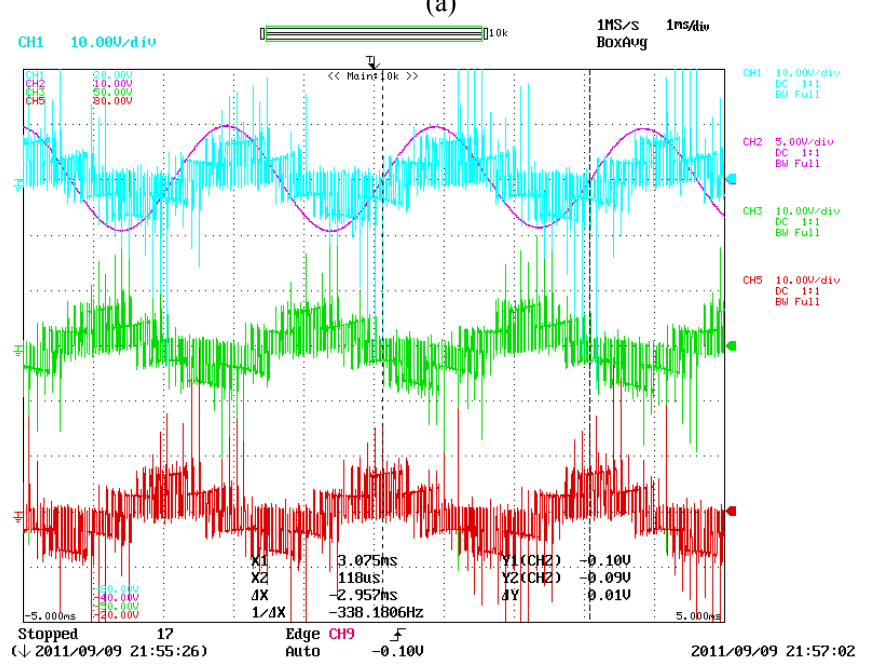

(b)

Fig. 21. The measured phase voltage and current waveforms under flux-weakening conditions, (a) with 60degrees current phase advanced angle, (b) with 85 degrees current phase advanced angle. (CH1 - Phase A voltage, $\mathrm{CH} 3$ - Phase B voltage, $\mathrm{CH} 5$ - Phase $\mathrm{C}$ voltage, $\mathrm{CH} 2$ - Phase A current.)

variations of measured speed and power output of the prototype against the advanced firing angle are compared with the corresponding predicted ones in Fig.19. It can be observed that the measured speed of machine especially with large phase advanced angle is higher than the predicted one as the measured phase back EMF is lower than the predicted one while the measured $d$-axis inductance are higher. However, the predicted power outputs of the machine are still higher than the measured ones over the whole flux-weakening region, as a result of the overestimated torque output shown in Fig.20. Clearly, the prototype shows an excellent capability of flux-weakening, when the base speed of $120 \mathrm{rpm}$ is extended to over 900rpm when the firing angle advances from 0 to just over 80 degrees during the experimental tests. The speed range of the constant power region for the prototype machine is from $120 \mathrm{rpm}$ to over 420rpm. Moreover, the corresponding profiles of predicted and measured efficiency and torque output against the advanced firing angle are shown and compared in Fig.20. The measured torque output is much lower than the estimated one due to the lower measured phase back EMF and higher measured inductances. Furthermore, the measured machine efficiency generally is smaller than the predicted one as shown 
in Fig. 20. However, it can be inspected that the efficiency of the prototype maintains well above $60 \%$ over most of the field-weakening region. In fact, the efficiency only starts to drop rapidly when the advanced firing angle exceeds 75 degrees, corresponding to a speed of over 420rpm. In practice, it is unlikely that the vehicle's speed will sustain at the extreme limit of the field weakening region. Taking the aforementioned factors into account and allowing for errors due to measurement and instrumentation, the agreements between the predicted and measured results are considered satisfactory. Fig.21 provides the experimental snapshots of the waveforms of the three phase voltage and the current during the flux weakening tests, one at advanced firing angle of 60 degrees shown in Fig.21(a), and another at 85 degrees shown in Fig.21(b). Evidently, the results confirm the operations of the machine at the extended flux-weakening region. With an advanced firing angle of 75 degrees, the machine's maximum operational speed of 420rpm at rated power output, 3.5 times the base speed, has been achieved and demonstrated.

\section{CONCLUSION}

A novel outer-rotor FSPM machine is proposed, and studied comprehensively for its application in light in-wheel traction vehicles. The combinations of pole and slot numbers are examined for maximal back-EMF and minimal cogging torque. Sizing equations are derived for preliminary design, and FEA methods are used for further design optimization. Special efforts are taken to improve the machine torque performance and also to enhance its flux-weakening capability. Extensive experimental tests are undertaken for a prototype machine based on an overall optimized design. The experimental results are in reasonable agreements with the predicted results from the FEA models, and confirm that the outer-rotor FSPM machine is suitable for traction propulsions thanks to its relatively high efficiency and high flux-weakening capability over the operational speed range. Although the outer-rotor FSPM prototype has been operated at relatively light traction loads, it is envisaged this type of machine configuration can be used for higher power applications.

\section{ACKNOWLEDGMENT}

This work was supported by National Natural Science Foundation of China (NSFC50677061) and Qiangjiang Professionals Program of Zhejiang Province (2006R10014), and carried out under the collaborative Memorandum of Understanding between Cranfield University and Zhejiang University.

\section{REFERENCES}

[1] P. Fairley, "China's cyclists take charge: electric bicycles are selling by the millions despite efforts to ban them," IEEE Spectrum, vol. 42, no. 6, pp. 54-69, June 2005.

[2] Mulhall, P. ; Lukic, S.M. ; Wirasingha, S.G. ; Young-Joo Lee ; Emadi, A. " Solar-Assisted Electric Auto Rickshaw Three-Wheeler,", IEEE Trans. On Vehicular Technology, vol. 59, no. 5, pp. 2298 - 2307, Jun 2010.
[3] S. E. Rauch, and L. J. Johnson, "Design principles of flux-switching alternators," AIEE Trans., Power Apparatus Syst. Part III, vol. 74, no. 3, pp. 1261-1268, Jan. 1955.

[4] E. Hoang, A. H. Ben-Ahmed, and J. Lucidarme, "Switching flux PM polyphased synchronous machines," in Proc. $7^{\text {th }}$ Eur. Conf. Power Electron. Appl., Sep. 1997, vol. 3, pp. 903-908.

[5] Z. Q. Zhu, Y. Pang, D. Howe, S. Iwasaki, R. Deodhar, and A. Pride, "Analysis of electromagnetic performance of flux-switching PM machines by non-linear adaptive lumped parameter magnetic circuit model," IEEE Trans. Magn., vol. 41, no. 11, pp. 4277-4287, Nov. 2005.

[6] Y. Chen, Z. Q. Zhu, and D. Howe, "Three-dimensional lumped parameter magnetic circuit model for analyzing single-phase flux-switching PM motor," IEEE Trans. Ind. Appl., vol. 44, no. 6, pp. 1701-1710, Nov./Dec. 2008.

[7] E. Ilhan, B. L. J. Gysen, J. J. H. Paulides, and E. A. Lomonova, "Analytical hybrid model for flux switching permanent magnet machines," IEEE Trans. Magn., vol. 46, no. 6, pp. 1762-1765, Jun. 2010

[8] J. T. Chen, and Z. Q. Zhu, "Influence of the rotor pole number on optimal parameters in flux-switching PM brushless AC machines by the lumped-parameter magnetic circuit model," IEEE Trans. Ind. Appl., vol. 46, no. 4, pp. 1381-1388, Jul./Aug. 2010.

[9] Z. Q. Zhu, and J. T. Chen, "Advanced flux-switching permanent magnet brushless machines," IEEE Trans. Magn., vol. 46, no. 6, pp. 1447-1453, Jun. 2010.

[10] Y. Amara, E. Hoang, M. Gabsi, M. Lecrivain, and S. Allano, "Design and comparison of different flux-switching synchronous machines for an aircraft oil breather application," Eur. Trans. Elect. Power, vol. 15, no. 6, pp. 497-511, 2005.

[11] Y. Cheng, C. Pollock, and H. Pollock, "A permanent magnet flux switching motor for low energy axial fans," in Proc. IEEE Ind. Appl. Soc. $40^{\text {th }}$ Annu. Meet., Oct. 2005, vol. 3, pp. 2168-2175.

[12] W. Fei, and J. X. Shen, "Novel permanent magnet switching flux motors," in Proc. $41^{\text {st }}$ Int. Universities Power Eng. Conf., Sep. 2006, vol. 2, pp. 729-733.

[13] Z. Q. Zhu, J. T. Chen, and D. Howe, "Analysis of a novel multi-tooth flux-switching PM brushless ac machine for high torque direct-drive applications," IEEE Trans. Magn., vol. 44, no. 11, pp. 4313-4316, Nov. 2008.

[14] A. S. Thomas, Z. Q. Zhu, R. L. Owen, G. W. Jewell, and David Howe, "Multiphase flux-switching permanent-magnet brushless machine for aerospace application," IEEE Trans. Ind. Appl.., vol. 45, no. 6, pp. 1071-1981, Nov./Dec. 2009.

[15] R. L. Owen, Z. Q. Zhu, A. S. Thomas, G. W. Jewell, and D. Howe, "Alternate poles wound flux-switching permanent-magnet brushless AC machines," IEEE Trans. Ind. Appl.., vol. 46, no. 2, pp. 790-797, Mar./Apr. 2010.

[16] T. Raminosoa, C. Gerada, and M. Galea, "Design considerations for a fault-tolerant flux-switching permanent-magnet machine," IEEE Trans. Ind. Electron., vol. 58, no. 7, pp. 2818-2825, July 2011.

[17] W. Hua, M. Cheng, Z. Q. Zhu, and D. Howe, "Analysis and optimization of back-emf waveform of a flux-switching PM motor," IEEE Trans. Energy Conversion, vol. 23, no. 3, pp. 727-733, Sep. 2008.

[18] J. T. Chen, and Z. Q. Zhu, "Winding configuration and optimal stator and rotor pole combination of flux-switching PM brushless AC machines," IEEE Trans. Energy Conversion, vol. 25, no. 2, pp. 293-302, Jun. 2010.

[19] J. T. Chen, and Z. Q. Zhu, "Comparison of all- and alternate-poles-wound flux-switching PM machines having different stator and rotor pole numbers," IEEE Trans. Ind. Appl.., vol. 46, no. 4, pp. 1406-1415, Jul./Aug. 2010.

[20] J. T. Chen, Z. Q. Zhu, S. Iwasaki, and R. P. Deodhar, "A novel E-core switched flux PM brushless AC machine," IEEE Trans. Ind. Appl.., vol. 47, no. 3, pp. 1273-1282, May/Jun. 2011.

[21] W. Fei, P. C. K. Luk, J. X. Shen, B. Xia, and Y. Wang, "Permanent-magnet flux-switching integrated starter generator with different rotor configurations for cogging torque and torque ripple mitigations," IEEE Trans. Ind. Appl.., vol. 47, no. 3, pp. 1247-1256, May/Jun. 2011.

[22] J. T. Chen, Z. Q. Zhu, S. Iwasaki, and R. P. Deodhar, "Influence of slot opening on optimal stator and rotor pole combination and electromagnetic performance of switched-flux PM brushless AC machines," IEEE Trans. Ind. Appl.., vol. 47, no. 4, pp. 1681-1691, Jul./Aug. 2011. 
[23] C. F. Wang, J. X. Shen, L. L. Wang, and K. Wang, "A novel permanent magnet flux-switching linear motor," in Proc. $4^{\text {th }}$ IET Conf. Power Electronic, Machines and Drives, 2008, pp. 116-119.

[24] J. B. Wang, W. Y. Wang, K. Atallah, and D. Howe, "Design considerations for tubular flux-switching PM machines," IEEE Trans. Magn., vol. 44, no. 11, pp. 4026-4032, Nov. 2008.

[25] C. F. Wang, J. X. Shen, Y. Wang, L. L. Wang, and M. J. Jin, "A new method for reduction of detent force in PM flux-switching linear motors," IEEE Trans. Magn., vol. 45, no. 6, pp. 2843-2846, Jun. 2009.

[26] M. J. Jin, C. F. Wang, J. X. Shen, and B. Xia, "A modular PM flux-switching linear machine with fault-tolerant capability," IEEE Trans. Magn., vol. 45, no. 8, pp. 3179-3186, Aug. 2009.

[27] W. Min, J. T. Chen, Z. Q. Zhu, Y. Zhu, M. Zhang, and G. H. Duan, "Optimization and comparison of novel E-core and C-core linear switched flux PM mahcines," IEEE Trans. Magn., vol. 47, no. 8, pp.2134-2141, Aug. 2011.

[28] W. Fei, P. C. K. Luk, J. X. Shen, and Y. Wang, "A novel outer-rotor PM flux-switching machine for urban electric vehicle propulsion," in Proc. $3^{\text {rd }}$ Int. Conf. Power Electon. Syst. Appl., May 2009, pp. 1-6.

[29] B. Stumberger, A. Hamler, M. Trlep, and M. Jesenik, "Analysis of interior permanent magnet synchronous motor designed for flux weakening operation," IEEE Trans. Magn., vol. 37, no. 5, pp. 3644-3647, Sep. 2001.

[30] R. Dutta, and M. F. Rahman, "Design and analysis of an interior permanent magnet (IPM) machine with very wide constant power operation range," IEEE Trans. Energy Conversion, vol. 23, no. 1, pp. 25-33, Mar. 2008.

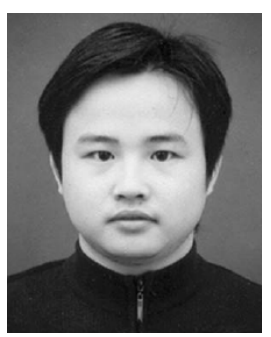

Weizhong Fei was born in Zhejiang, China, 1981 $\mathrm{He}$ received the B.Eng. and M.Eng. degrees in electrical engineering from Zhejiang University, Hangzhou, China, in 2004 and 2006, respectively, and the $\mathrm{Ph} . \mathrm{D}$ degree in electrical engineering from Cranfield University, Shrivenham, U.K., in 2010

He was a Research Associate with the University of Sheffield, U.K., from 2011 to 2012. He is currently a Research Fellow/Lecturer with Power Electronics and Machines Group in the School of Engineering, Cranfield University, U.K. His main research interests include design and applications of permanent magnet machines and drives.

Dr. Fei was the recipient of IET Premium Award on Electric Power Applications in 2011.

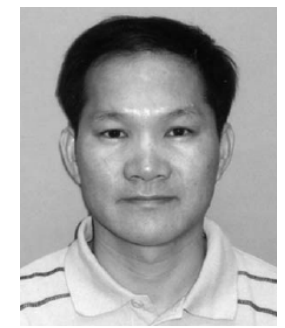

Patrick Chi Kwong Luk (M'92-SM'08) was born in Hong Kong in 1960. He received the high diploma with merit (BSc) from Hong Kong Polytechnic University in 1983, Mphil from the University of Sheffield, Sheffield, U. K. in 1989, and Ph. D from the University of Glamorgan, Wales, U.K. in 1992, all in electrical engineering.

He started his career as assistant engineer at GEC (HK), then as application engineer at Polytek Engineering Co (HK), and as Researcher at the H. K. Industrial Centre. Since 1988, he had held academic positions at the Uinversity of Glamorgan, Robert Gordon and Herfordshire. He joined Cranfield University as senior lecturer in 2002. He is the founder and head of the Power Electronics and Machines Group in the School of Engineering, Cranfield University, U.K. He has published over 100 papers on electric drives and energy conversion. His main research interests are in electrical drives for electric vehicles and renewable energy applications, and power electronics applications in future smartgrids.

Dr. Luk was the recipient of IET Premium Award on Electric Power Applications in 2011.

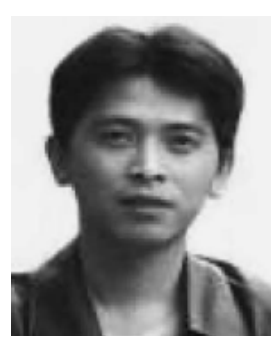

Jian Xin Shen (M'98-SM'03) was born in Zhejiang, China, in 1969. He received the B. Eng. and M.Sc. degrees in electrical engineering from Xi' an Jiaotong University, Xi'an, China, in 1991 and 1994, respectively, and the $\mathrm{Ph}$. D degree in electrical engineering from Zhejiang University, Hangzhou, China, in 1997.

He was with Nanyang Technological University, Singapore, from 1997 to 1999 , the University of Sheffield, Sheffield, U.K., from 1999 to 2002, and the U.K. Research Centre, IMRA Europe SAS, Brighton, U.K., from 2002 to 2004. Since 2004, he has been a Professor of electrical engineering at Zhejiang University. He has published more than 110 papers and is the holder of 17 patents. His main research interests include the topologies, control, and applications of permanent-magnet machine drives.

Dr. Shen was the recipient of a Prize Paper Award from the IEEE Industry Applications Society in 2003 and a Best Paper Award from EVER Monaco in 2010.

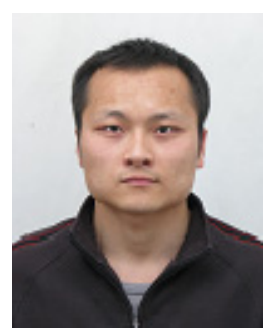

Yu Wang was born in Zhejiang, China, in 1983. He received the B.Eng. and $\mathrm{Ph}$. D degrees in electrical engineering from Zhejiang University, Hangzhou, China, in 2006 and 2011, respectively.

$\mathrm{He}$ has been a Research Associate with the University of Sheffield, U.K. since 2012. His main research interests include topologies control, and applications of flux-switching permanent-magnet machine drives.

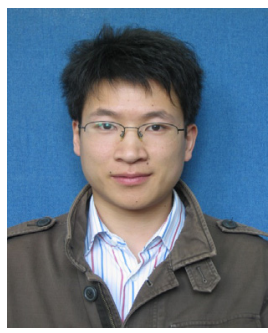

Mengjia Jin was born in Zhejiang, China, in 1980. $\mathrm{He}$ received the B. Eng. and $\mathrm{Ph}$. D degrees from Zhejiang University, Hangzhou, China, in 2001 and 2006, respectively.

$\mathrm{He}$ has been with the College of Electrical Engineering, Zhejiang University, since 2006, where he currently is an associate professor. His major research interests are electrical machine design and drives.

Dr. Jin was the recipient of a Best Paper Award from EVER Monaco in 2010. 